\title{
Rancang Bangun Sistem Ultrasound Assisted Extraction (UAE) dengan Otomasi Pengaturan Suhu dan Volume Pelarut
}

\author{
Humairoh Ratu Ayu ${ }^{1 *}$, Suryono Suryono², dan Jatmiko Endro Suseno ${ }^{2}$ \\ ${ }^{1}$ Jurusan Fisika, Fakultas Matematika Ilmu Pengetahuan Alam, Universitas Lampung, Indonesia \\ ${ }^{2}$ Jurusan Fisika, Fakultas Sains dan Matematika, Universitas Diponegoro, Indonesia \\ *humairoh.ratu@fmipa.unila.ac.id
}

\section{ABSTRACT}

In this research, a design of temperature and solvent volume has been completed. This system consists of pump, microcontroller, thermocouple, thermocontroller and LM35 temperature sensor which aims to avoid extracting dilution and increase mass transfer so that it gets better extraction results. The pump turns on in accordance with the instructions given to the microcontroller then the ADC value is read by the LM35 temperature sensor which is then converted to a temperature value. Based on the results of research conducted, the system is able to control the volume of the solvent with an error value of $2.38 \%$, monitor the temperature in the extraction container using an LM35 temperature sensor with an error value of $0.70 \%$ and control the temperature using a thermocontroler with a system stability of $96.16 \%$.

Keyword: setting temperature, solvent volume, sensor, microcontroller

\section{ABSTRAK}

Pada penelitian ini telah dilakukan rancang bangun sistem pengaturan suhu dan volume pelarut pada ultrasound assisted extraction. Sistem ini terdiri dari pompa, mikrokontroler, termocouple, termocontroller dan sensor suhu LM35 yang bertujuan untuk menghindari pengenceran ekstrak dan meningkatkan transfer massa sehingga mendapatkan hasil ekstraksi yang lebih baik. Pompa menyala sesuai dengan perintah yang diberikan ke mikrokontroler selanjutnya dilakukan pembacaan nilai ADC oleh sensor suhu LM35 yang kemudian dikonversi ke dalam nilai temperatur. Berdasarkan hasil penelitian yang telah dilakukan, sistem mampu mengontrol volume pelarut dengan nilai error sebesar 2,38\%, memantau suhu dalam wadah ekstraksi menggunakan sensor suhu LM35 dengan nilai error sebesar $0,70 \%$ dan mengontrol suhu menggunakan termokontroler dengan kestabilan sistem sebesar $96,16 \%$.

Kata kunci: pengaturan suhu, volume pelarut, sensor, mikrokontroler

\section{PENDAHULUAN}

Perkembangan teknologi saat ini banyak dimanfaatkan dalam bidang industri makanan dan kesehatan, salah satu contohnya untuk membuat bahan baku ekstrak tumbuhan obat. Proses ekstraksi yaitu pemisahan suatu zat dari campurannya dengan menggunakan sejumlah pelarut. Metode ekstraksi yang biasa digunakan beberapa tahun terakhir yaitu metode ekstraksi konvensional seperti maeserasi, soxhlet, dan hidrodistilasi yang menggunakan volume pelarut dalam jumlah besar dan memerlukan waktu ekstraksi yang lama ${ }^{[1]}$. Untuk mengatasi kelemahan metode tersebut berbagai teknik ekstraksi baru telah diusulkan untuk ekstraksi senyawa bioaktif dari makanan, salah satunya metode ultrasound assisted extraction (UAE) ${ }^{[2]}$ yang menggunakan lebih sedikit volume pelarut, memperpendek waktu ekstraksi, dan hemat energi ${ }^{[3]}$. 
Dalam tinjauan literatur, penggunaan metode ultrasound semakin banyak diminati dibandingkan metode konvensional, karena memperpendek waktu ekstraksi. Penggunaan ultrasound dapat memperbaiki komponen bioaktif yang sensitif terhadap panas dengan proses pada suhu yang lebih rendah, dan efek mekanis ultrasound memberikan penetrasi pelarut yang lebih besar ke dalam bahan seluler, sehingga meningkatkan perpindahan massa sedangkan gangguan dinding sel biologis memudahkan pelepasan isinya ${ }^{[4]}$. Oleh karena itu, metode ekstraksi dengan bantuan ultrasonik lebih efektif daripada metode konvensional ${ }^{[5]}$ karena memiliki dua keunggulan utama yaitu mengurangi waktu ekstraksi dan penggunaan volume pelarut ${ }^{[6]}$.

Proses ekstraksi dapat dipengaruhi oleh beberapa faktor seperti suhu dan volume pelarut ${ }^{[7]}$. Pengaturan volume pelarut dilakukan dengan beberapa tahapan, yaitu sampel dimasukkan ke dalam extraction chamber yang dilengkapi dengan ultrasonic bath. Selanjutnya pelarut ekstraksi dipompa ke dalam extraction chamber yang bertujuan untuk menghindari pengenceran ekstrak dan meningkatkan transfer massa sehingga mendapatkan hasil ekstraksi yang lebih baik ${ }^{[8]}$. Jumlah volume pelarut yang terlalu besar menyebabkan hasil ekstraksi menurun. Pada penelitian ini pelarut yang digunakan adalah etanol. Pelarut etanol memiliki dua sisi yang terdiri dari gugus $\mathrm{OH}$ yang bersifat polar dan gugus $\mathrm{CH}_{2} \mathrm{CH}_{3}$ yang bersifat non polar. Sifat non polar inilah yang membuat etanol mampu mengekstrak kandungan senyawa fenolik di dalam daun jambu biji secara optimal [9].

Selain itu, proses esktraksi pada suhu tinggi mampu memberikan hasil yang optimum dan mempercepat proses ekstraksi. Hal ini karena menurunnya viskositas pelarut pada suhu tinggi memudahkan pelarut menembus objek yang diekstraksi dan meningkatnya transfer massa selama proses ekstraksi ${ }^{[10]}$. Penelitian ini bertujuan untuk membangun sistem instrumentasi menggunakan gelombang ultrasonik untuk ekstraksi tumbuhan obat yang dilengkapi dengan pengaturan suhu, pemantau suhu dan pengaturan volume pelarut.

\section{METODE}

\section{Pembuatan Sistem Instrumentasi Menggunakan Gelombang Ultrasonik}

Sistem instrumentasi penggunaan gelombang ultrasonik dirancang untuk melakukan proses ekstraksi secara otomatis. Sistem ini terdiri dari pompa dorong yang berfungsi untuk mengalirkan pelarut ke wadah ekstraksi. Pompa dorong dihubungkan ke relay yang berfungsi untuk menyalakan dan mematikan pompa saat volume pelarut yang diinginkan tercapai. Termokontroler berfungsi untuk mempertahankan suhu yang terukur oleh termokopel sesuai dengan nilai set point suhu yang diberikan. Heater beroperasi karena adanya relay yang dikontrol oleh mikrokontroler. Apabila suhu yang terukur oleh sensor telah mencapai nilai set point suhu yang diberikan, maka relay mematikan fungsi heater. Relay bekerja sesuai dengan perintah program yang diberikan ke mikrokontroler. Selanjutnya data program yang telah diproses oleh mikrokontroler dikirim ke komputer ditampilkan pada aplikasi software Borland Delphi sebagai media interface. Diagram sistem UAE ditunjukkan pada Gambar 1. 


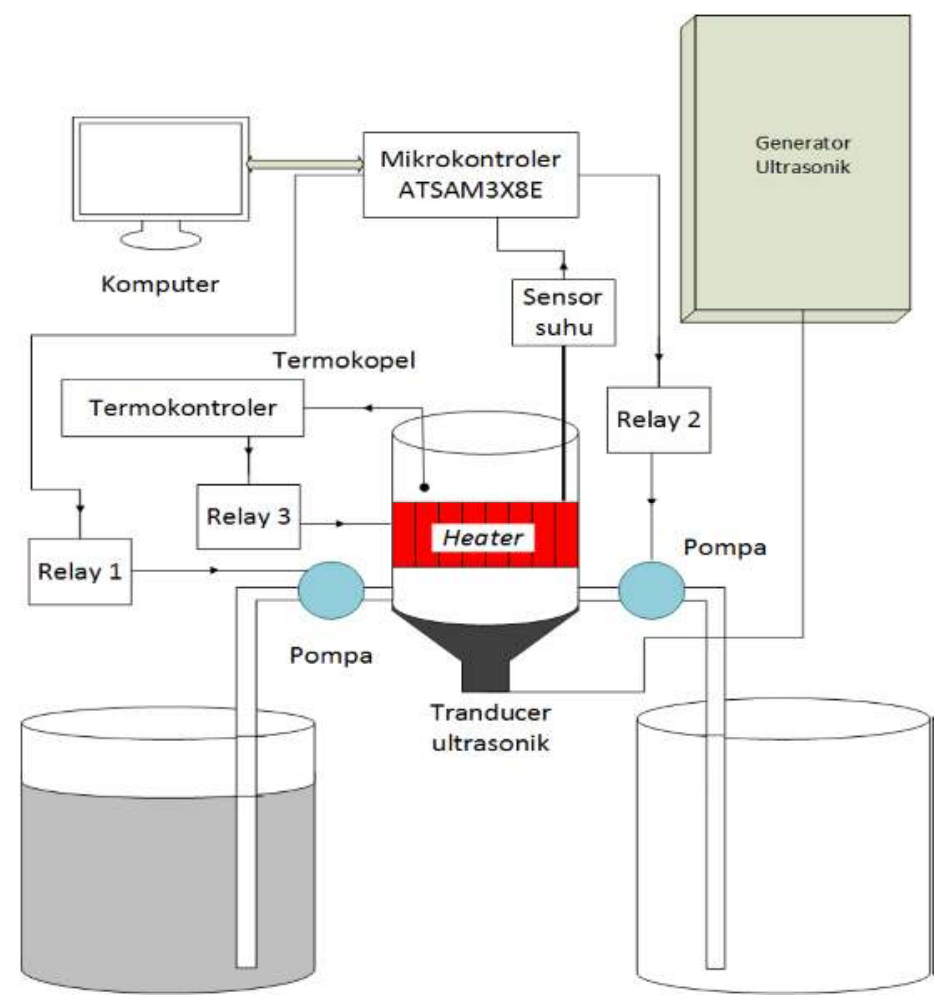

Gambar 1. Diagram Sistem UAE

\section{Rangkaian Sistem Pompa}

Pompa berfungsi untuk menyerap pelarut dalam suatu bejana dan mendorongnya ke dalam wadah ekstraksi. Pompa dapat mengalirkan pelarut hingga 1,5-2 L/menit. Pengaturan volume pelarut dirancang agar pompa mampu mengalirkan volume pelarut sesuai dengan nilai set point volume yang diberikan. Pompa beroperasi karena adanya relay yang dikontrol oleh mikrokontroler. Nilai set point volume yang diberikan kemudian dikirim ke mikrokontroler untuk menyalakan pompa dan mengalirkan pelarut sesuai dengan nilai set point volume yang diberikan. Rangkaian sistem pompa ditunjukkan pada Gambar 2.

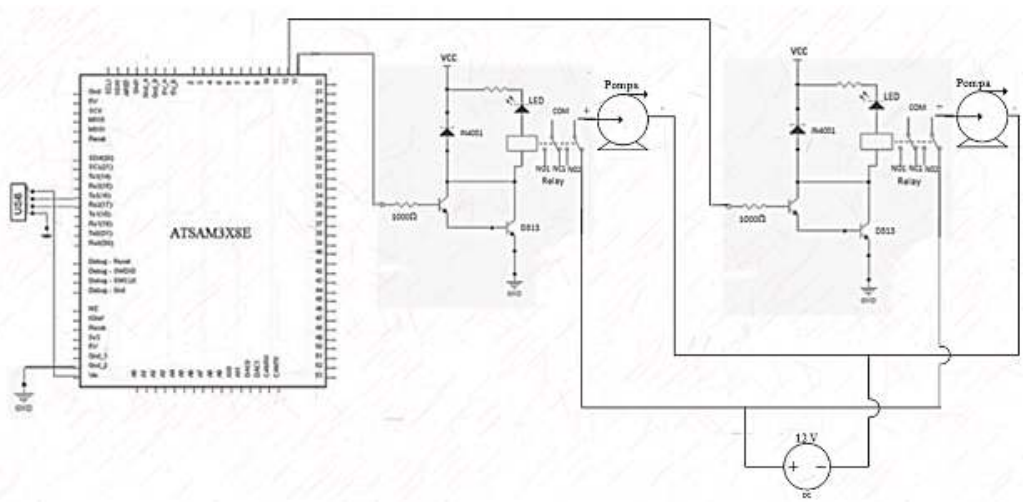

Gambar 2. Rangkaian sistem pompa 


\section{Rangkaian Sistem Sensor Suhu}

Sensor suhu LM35 merupakan sensor yang berfungsi untuk mengukur suhu larutan di dalam wadah ekstraksi. Besaran suhu yang terdeteksi diubah menjadi besaran listrik dalam bentuk tegangan. Sensor suhu LM35 memiliki 3 kaki di antaranya yaitu, kaki 1 merupakan sumber tegangan, kaki 2 sebagai sinyal output dan kaki 3 adalah ground. Rangkaian sensor suhu LM35 ditunjukkan pada Gambar 3.

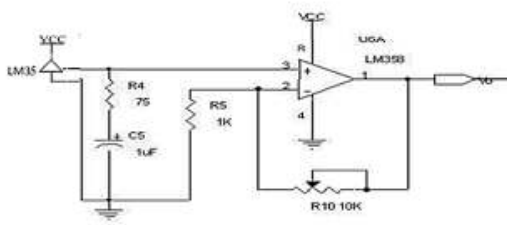

Gambar 3. Rangkaian sistem sensor suhu LM35

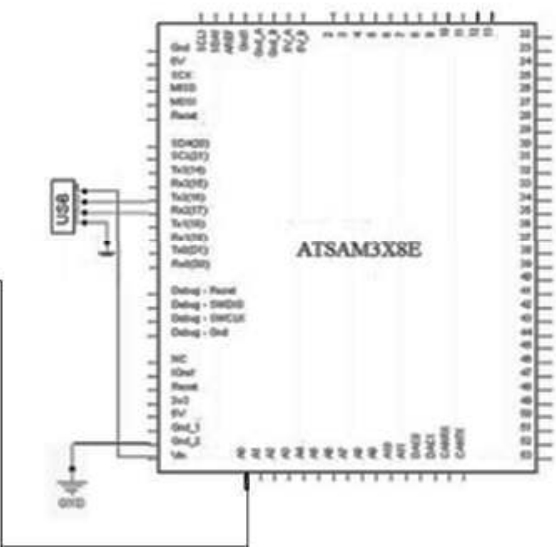

\section{Kriteria Pengujian Sistem UAE}

Pengujian sistem UAE yang dibangun dilakukan dengan menghitung nilai error yang diperoleh dari persamaan berikut ${ }^{[11]}$ :

$$
\text { Error }=\left(\left|\frac{T_{s \tan d a r}-T_{\text {alat }}}{T_{s \tan d a r}}\right|\right) \times 100 \%
$$

Pada persamaan tersebut $T_{\text {standar }}$ adalah nilai yang diperoleh dari alat ukur standar dan $T_{\text {alat }}$ adalah nilai yang diperoleh dari sistem yang dibangun dengan toleransi nilai error sebesar $\pm 5 \%$. Sistem yang dibangun dikatakan berhasil jika nilai error rata-rata yang diperoleh kurang dari $5 \%{ }^{[12]}$.

\section{HASIL DAN PEMBAHASAN}

\section{Hasil Karakterisasi Sistem Pengaturan Volume Pelarut}

Pada pengujian ini, pompa menyala karena perintah yang diberikan ke mikrokontroler dan pompa mati setelah volume pelarut yang mengalir sesuai dengan nilai set point volume yang diberikan. Karakterisasi dilakukan untuk mendapatkan hubungan antara jumlah volume yang mengalir terhadap waktu yang ditunjukkan dalam grafik karakterisasi pada Gambar 4. 


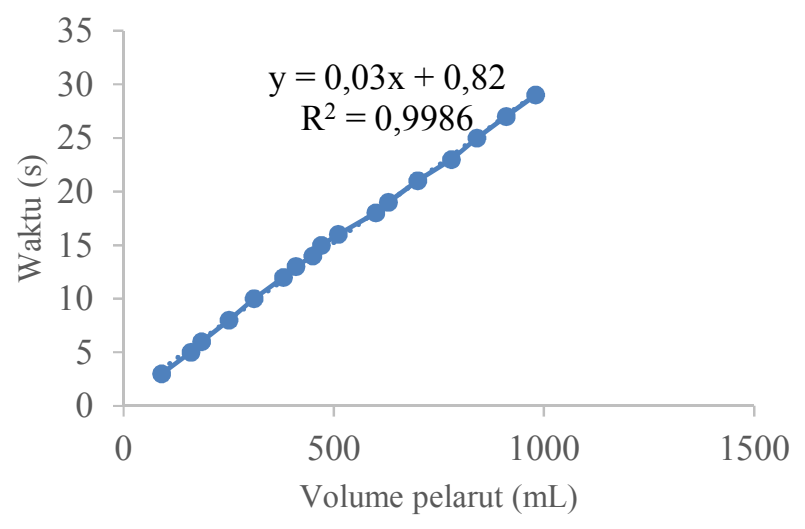

Gambar 4. Grafik karakterisasi volume terhadap waktu

Berdasarkan grafik tersebut, nilai koefisien determinasi $\left(\mathrm{R}^{2}\right)$ mendekati 1 artinya terdapat hubungan antara volume yang mengalir melalui pompa terhadap waktu dengan nilai $\mathrm{R}^{2}$ sebesar 0,9986. Persamaan yang diperoleh dari Gambar 4 adalah:

$$
y=0,03 x+0,82
$$

$y$ adalah waktu dan $x$ adalah volume. Persamaan 2 digunakan untuk mengkonversi nilai volume ke dalam bentuk waktu pada pembacaan komputer yang ditampilkan melalui program antarmuka komputer sebagai media interface. Pengujian sistem pengaturan volume pelarut dilakukan dengan membandingkan antara nilai volume yang dimasukkan sebagai nilai set point volume dengan nilai volume yang keluar dari sistem. Hasil pengujian tersebut disajikan dalam grafik pada Gambar 5.

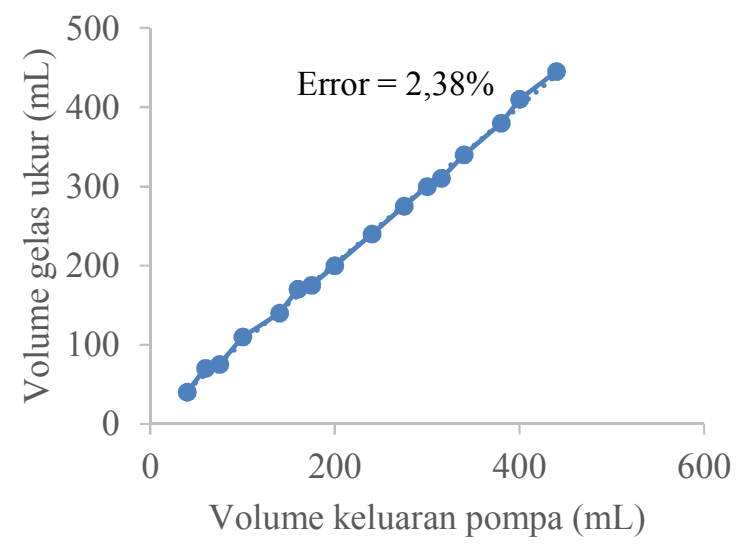

Gambar 5. Grafik hubungan volume keluaran pompa dengan gelas ukur

Gambar 5 dapat dilihat bahwa nilai error rata-rata yang dihasilkan 2,38\% nilai tersebut menunjukkan sistem yang dirancang mampu untuk melakukan pengaturan volume pelarut. Tetapi, dari hasil pengujian masih terdapat perbedaan nilai ukur yang disebabkan adanya faktor-faktor yang mempengaruhinya yaitu, adanya getaran dan panas yang terjadi pada pompa. Hal ini menyebabkan penurunan daya pada pompa sehingga mengakibatkan volume pelarut yang keluar kurang akurat. 


\section{Hasil Pengujian Pembacaan Sensor Suhu LM35}

Sinyal tegangan keluaran sensor LM35 masih berupa sinyal analog, keluaran sensor yang terbaca oleh mikrokontroler diubah terlebih dahulu menjadi sinyal digital, kemudian sinyal tersebut dikirim ke komputer dan ditampilkan dalam aplikasi program Borland Delphi. Untuk mengkonversi pembacaan ADC dari sensor ke dalam derajat Celcius diperlukan karakterisasi antara pembacaan ADC dengan termometer digital sebagai suhu standar. Grafik karakterisasi ditunjukkan pada Gambar 6. Gambar 6 menunujukkan bahwa terdapat hubungan antara pembacaan ADC dari sensor suhu terhadap suhu yang diukur dengan alat ukur standar dengan nilai $\mathrm{R}^{2}$ sebesar 0,9996 . Persamaaan yang diperoleh adalah:

$$
y=0,03 x+0,37
$$

$y$ adalah nilai suhu standar dan $x$ adalah nilai pembacaan ADC dari sensor. Persamaan tersebut dimasukkan ke dalam program Borland Delphi sehingga didapatkan nilai suhu dari pembacaan sensor yang sesuai dengan suhu pada alat ukur standar. Selanjutnya dilakukan pengujian dengan membandingkan data hasil pembacaan sensor suhu yang telah dikarakterisasi dengan pembacaan termometer digital sebagai suhu standar. Hasil pengujian tersebut ditunjukkan pada Gambar 7.

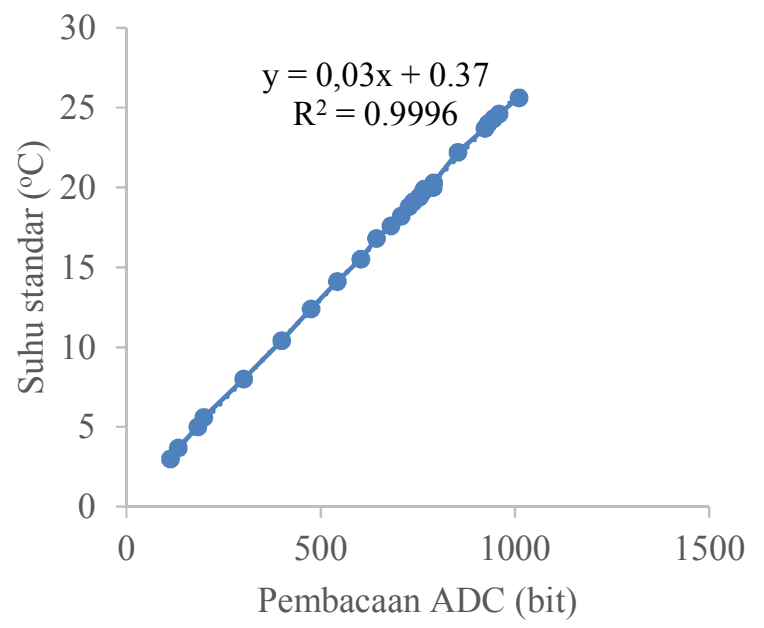

Gambar 6. Grafik karakterisasi antara pembacaan ADC terhadap suhu standar 


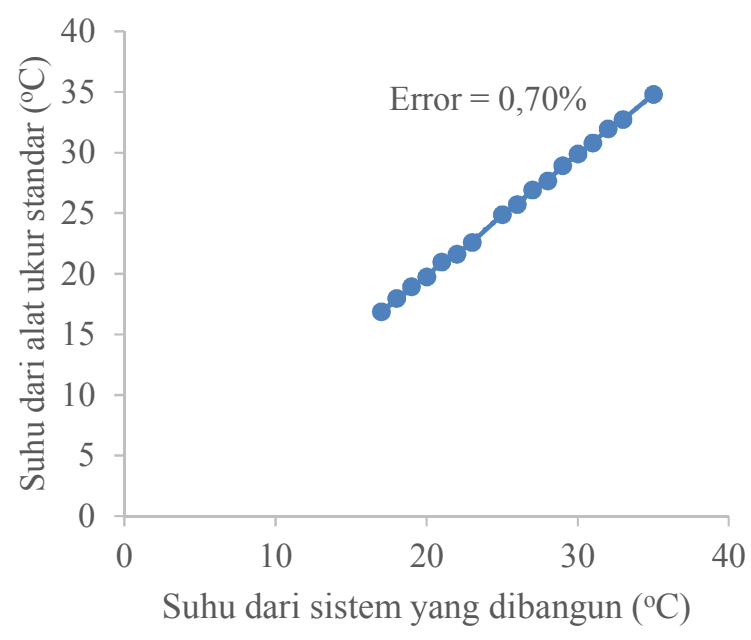

Gambar 7. Grafik hasil kalibrasi sensor suhu

Berdasarkan grafik yang ditunjukkan pada Gambar 7 dapat dilihat bahwa nilai error ratarata diperoleh $0,70 \%$ nilai tersebut menunjukkan bahwa sistem yang dirancang mampu untuk melakukan pengukuran suhu dengan nilai error yang sangat rendah. Dari hasil pengujian masih terdapat perbedaan nilai ukut yang disebabkan beberapa faktor diantaranya yaitu karena adanya perbedaan sensitifitas antara sensor dengan termometer digital. Selain itu sensor suhu LM35 beroperasi dengan membutuhkan sumber tegangan 4V - 30V dan memiliki karakteristik self-heating yang akan terjadi apabila arus yang melewatinya melebihi $1 \mathrm{~mA}$. Hal itu menyebabkan hasil pengukuran sensor suhu tidak sesuai dengan nilai yang sebenarnya.

\section{Hasil Pengujian Pengontrol Suhu}

Pada proses ekstraksi parameter suhu dikontrol menggunakan termokontroler yang menerima data perubahan suhu dari termokopel. Pada pengujian ini ditentukan nilai set point pembacaan suhu $35^{\circ} \mathrm{C}$ Saat termokopel mendeteksi suhu dalam wadah ekstraksi, hasil pembacaan suhu ditampilkan pada monitor termokontroler. Melalui pembacaan temperatur inilah yang akan menjadi indikasi melakukan pengontrolan terhadap aktuator berupa element heater. Berikut data hasil pengujian sistem kontrol suhu beserta kondisi heater ditunjukkan pada Tabel 1.

Berdasarkan Tabel 1 kondisi heater menyala saat suhu yang terukur dalam wadah ekstraksi $<35^{\circ} \mathrm{C}$ atau dibawah suhu set point, dan heater mati saat suhu yang terukur oleh termokopel $\geq 35^{\circ} \mathrm{C}$. Setelah dilakukan pengujian sistem kontrol suhu, selanjutnya dibuat grafik pengujian sistem kontrol suhu terhadap waktu berdasarkan nilai set point yang diberikan. Dari grafik tersebut dapat diketahui waktu respon sistem kontrol suhu untuk mencapai nilai set point. Grafik pengujian sistem kontrol suhu terhadap waktu disajikan pada Gambar 8. 
Tabel 1. Data hasil pengujian sistem kontrol suhu

\begin{tabular}{ccc}
\hline Waktu $(\mathrm{s})$ & Suhu $\left({ }^{\circ} \mathrm{C}\right)$ & Kondisi Heater \\
\hline 10 & 27 & ON \\
80 & 30 & ON \\
150 & 35 & OFF \\
240 & 39 & OFF \\
360 & 40 & OFF \\
440 & 39 & OFF \\
510 & 39 & OFF \\
590 & 38 & OFF \\
660 & 37 & $O F F$ \\
740 & 37 & $O F F$ \\
800 & 36 & $O F F$ \\
880 & 36 & $O F F$ \\
940 & 36 & $O F F$ \\
990 & 36 & $O F F$ \\
1010 & 35 & $O F F$ \\
1100 & 35 & $O F F$ \\
\hline
\end{tabular}

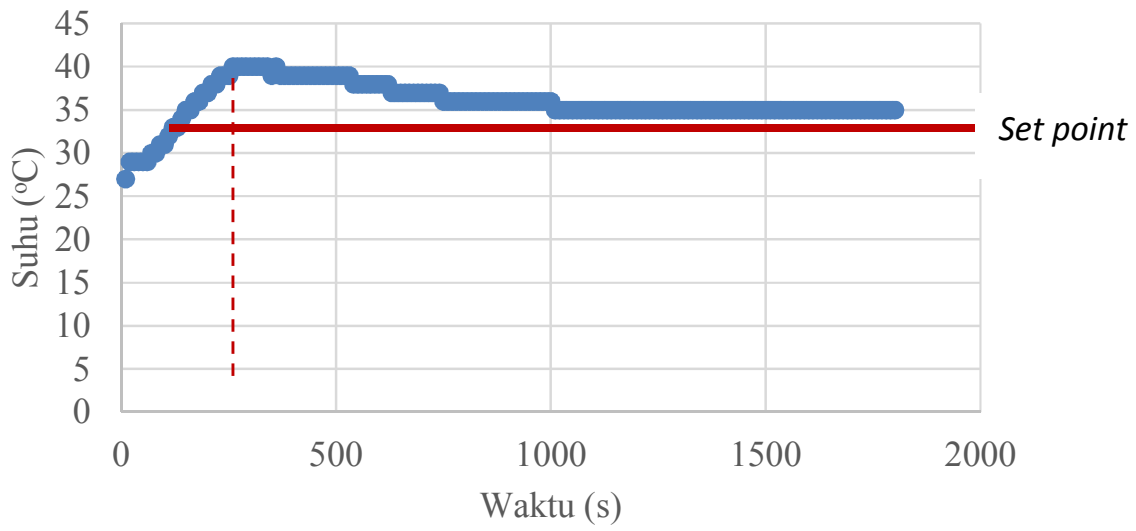

Gambar 8. Grafik pengujian sistem kontrol suhu terhadap waktu

Dari grafik tersebut dapat diketahui sistem mencapai nilai set point pada waktu ke-150 detik. Setelah itu suhu terus naik hingga mencapai $40^{\circ} \mathrm{C}$ pada waktu ke-260 detik, kemudian suhu turun dengan perlahan sampai suhu yang terdeteksi oleh termokopel sesuai dengan nilai set point yang diberikan. Untuk mencapai kestabilan sistem dengan nilai set point suhu $35^{\circ} \mathrm{C}$ dibutuhkan waktu 1010 detik atau sekitar 16,8 menit dengan nilai error yang diperoleh $3,84 \%$ sehingga kestabilan sistem yang telah dibuat sebesar $96,16 \%$.

\section{KESIMPULAN}

Telah berhasil dibangun sistem instrumentasi menggunakan gelombang ultrasonik untuk proses ekstraksi. Sistem dilengkapi dengan pengaturan volume pelarut, pengaturan suhu, pemantau suhu dan pewaktu ekstraksi otomatis. Sistem ini dapat bekerja dengan baik yang dibuktikan dengan nilai error yang rendah yaitu sebesar $2,38 \%$ dalam mengontrol volume pelarut, $0,70 \%$ dalam memantau suhu pada wadah ekstraksi menggunakan sensor suhu LM35 dan memiliki tingkat kestabilan sistem sebesar 96,16\%. 


\section{DAFTAR PUSTAKA}

1 Bonfigli, M., Godoy, E., Reinheimer, M. A., \& Scenna, N. J. 2017. Comparison between conventional and ultrasound-assisted techniques for extraction of anthocyanins from grape pomace. Experimental results and mathematical modeling. J. Food Eng. Vol. 207, $56-72$.

2 Jovanović, A. A., Đorđević, V. B., Zdunić, G. M., Pljevljakušić, D. S., Šavikin, K. P., Gođevac, D. M., \& Bugarski, B. M. 2017. Optimization of the extraction process of polyphenols from Thymus serpyllum L. herb using maceration, heat- and ultrasoundassisted techniques. Sep. Purif. Technol. Vol. 179, 369-380.

3 Chemat, F., Vian, M. A., \& Cravotto, G. 2012. Green extraction of natural products: Concept and principles. Int. J. Mol. Sci. Vol. 13, 8615-8627.

4 Tao, Y., Zhang, Z., \& Sun, D. 2014. Ultrasonics Sonochemistry Kinetic modeling of ultrasound-assisted extraction of phenolic compounds from grape marc: Influence of acoustic energy density and temperature. Ultrason. - Sonochemistry. Vol. 21, 14611469.

5 He, B., Zhang, L. L., Yue, X. Y., Liang, J., Jiang, J., Gao, X. L., \& Yue, P. X. 2016. Optimization of Ultrasound-Assisted Extraction of phenolic compounds and anthocyanins from blueberry (Vaccinium ashei) wine pomace. Food Chem. Vol. 204, 70-76.

6 Veličković, D. T., Milenović, D. M., Ristić, M. S., \& Veljković, V. B. 2006. Kinetics of ultrasonic extraction of extractive substances from garden (Salvia officinalis L.) and glutinous (Salvia glutinosa L.) sage. Ultrason. Sonochem. Vol. 13, 150-156.

7 Ratu Ayu, H., Suryono, S., Endro Suseno, J., \& Kurniawati, R. 2018. Determination of the ultrasound power effects on flavonoid compounds from Psidium guajava L. using ANFIS. J. Phys. Conf. Ser. 1025.

8 Tadeo, J. L., Sánchez-Brunete, C., Albero, B., \& García-Valcárcel, A. I. 2010. Application of ultrasound-assisted extraction to the determination of contaminants in food and soil samples. Journal of Chromatography A. Vol. 1217, No. 16, 2415-2440.

9 Azis, T., Febrizky, S., \& Mario, A. D. 2014. Pengaruh Jenis Pelarut Terhadap Persen Yieldalkaloiddari Daun Salam India (Murraya Koenigii). Tek. Kim. Vol. 20, No. 2, 1-6.

10 Jovanović, A. A., Đorđević, V. B., Zdunić, G. M., Pljevljakušić, D. S., Šavikin, K. P., Gođevac, D. M., \& Bugarski, B. M. 2017. Optimization of the extraction process of polyphenols from Thymus serpyllum L. herb using maceration, heat- and ultrasoundassisted techniques. Sep. Purif. Technol. Vol. 179, 369-380.

11 Gorovoy, K., Tung, J., \& Poupart, P. 2010. Automatic speech feature extraction for cognitive load classification. Proc. Conf. Can. Med. Biol. Eng. Soc. Vol 33. No. 1.

12 Euramet. 2011. Guidelines on The Calibration of Temperature Indicators and Simulators by Electrical Simulation and Measurement. European Association of National Metrology Institutes. German. 